\title{
NUEVOS PARÁMETROS PARA EL ESTUDIO DE LA FAMILIA EN LA EDAD MODERNA: ALGUNOS EJEMPLOS GIENNENSES
}

\author{
POR \\ María Antonia Bel Bravo \\ Universidad de Jaén
}

\section{RESUMEN}

En este trabajo se articula una posibilidad de ampliar temáticamente los estudios sobre la familia en la Edad Moderna, incluyendo la perspectiva de los coetaneos y la renovación eclesiástica respecto al sacramento del matrimonio. Desde el punto de vista metodológico se trata de una apuesta por el tratamiento sustantivo de casos en lugar del enfoque estructuralista tradicional.

\begin{abstract}
In this research I tend to concentrate my attemption on the posibility of increasing thematic approaches when we refer to the study of family in the Modern Age by means of including nowadays opinions and the ecclesiastic renovation of the Holy Sacrament of Marriage. As a new step I try to include the analisys of concrete situations instead of taking into account structuralist approaches.
\end{abstract}

\section{CuzSTIONES Metodológicas}

Desde hace un par de décadas el tema de la familia viene siendo atractivo para los historiadores. Impulso considerable ha recibido, sin duda, gracias al puente tendido entre nuestra disciplina, la historia, y otras como la sociología y, sobre todo, la antropología social. Colaboración que viene dando frutos con mayor o menor acierto desde los años ochenta, aunque conviene no olvidar 
que junto con aportaciones de variado calado a la historia de la familia desde la antropología, otras lamentablemente son sesgadas y por este hecho pierden toda su fuerza para la investigación ${ }^{1}$. El reverso de esta moneda es el grado de dificultad para elaborar una síntesis con toda la información recabada, más leña para el fuego de la fragmentación que ya atraviesa la propia historia por cuantas formas de escribirla se han ensayado, aunque las diferencias epistemologicas no sean tan decisivas como aparentan en principio.

La historia de la familia se presta aún más que otros sectores a un posible desconcierto. No sólo, como de entrada advierte James Casey ${ }^{2}$, porque su mismo atractivo la convierte en peligrosa, $o$, si se quiere, inabarcable por su amplitud, sino también por la facilidad con que se aplican modelos, imprescindibles por otra parte a la hora de comenzar un trabajo científico. La idea de razón ilustrada nos ha llevado al prevalecimiento de los modelos sobre la realidad, obviando las peculiaridades regionales, y a menudo la propia identidad española; esto se aprecia con claridad en el estudio de la familia -y hay autores que así lo han advertido ${ }^{3}$ -

La visión mantenida en los estudios sobre la familia ha estado orientada a la transmisión del patrimonio, el entramado de las relaciones sociales, los mecanismos por medio de los cuales el orden social se reproduce... En torno a funciones de socialización, de establecimiento de redes de parentesco y alianza, de herencia y de acceso al poder, en definitiva. Se ha descuidado, cuando no se ha olvidado, esa otra perspectiva sobre el papel moral y educativo de la familia, que tanta preocupación suscitó en España y en el resto de Europa desde finales de la Edad Media. Se trata de esa otra visión que, dada por excepcional respecto del modelo, se suele dejar al margen de manera incorrecta, porque no se ha evaluado todavía su alcance en el pasado. Todo un conjunto de valores se transmitían a través del microcosmos familiar en la sociedad moderna, y la

I En mi opinión, son significativos, por deterministas, Jos planteamientos de J. Goody (1983), La evolución de la familia y del matrimonio en Europa, Barcelona, Herder, 1986. Cuando antepone los intereses económicos sobre los teologico-doctrinales, el autor no considera que la propia dinámica de la sociedad - caracterizada por un fuerte contenido religioso en la época a que se hace referencia, no lo olvidemos- - articula puntos de reflexión filosófica sobre la moral y sobre las obligaciones del hombre.

2 Casey, James (1989): Historia de la familia, «Espasa Calpe», Madrid, 1990. Se trata de un intento de síntesis con abundantes ejemplos tomados de la realidad espaniola.

3 «Sin embargo, la peculiaridad de lo que entendemos por España, no hace posible buscar corespondencias y tampoco hallar muchas correlaciones. Aplicar los modelos familiares establecidos By muy discutidosB para Europa, aunque se haya hecho en muchas ocasiones con brillantes análisis, revela una falta de reflexión sobre las identidades propias, que están suficientemente descubiertas, y que son muy importantes. No se trata tanto de someter el modelo propio ajustándolo, hasta donde es posible, con la comparación, cuanto de proyectarlo como tal» (RODRfGUEZ SÁNCHEZ, Ángel: La familia en la Edad Moderma, Madrid, Arco Libros, 1996, p. 54). 
comprensión de ésta exige el análisis de aquéllos. En mi opinión, la «historia de la familia» es un marco adecuado para llevarlo a cabo.

En este trabajo quiero precisamente aproximarme desde esta perspectiva, deteniéndome para ello en un aspecto concreto: cómo algunos principios que dan carne y vida al esqueleto estamental de la sociedad, durante el seiscientos y parte del setecientos, se concretan en el origen mismo de una familia -su principal vehículo de transmisión-, actuando en ocasiones como elementos matizadores de las estrategias matrimoniales que vienen captando la atención de los investigadores. Como resultado la sociedad adquiere unos rasgos específicos que no pueden ignorarse ${ }^{4}$.

Mi propuesta es abordar el tema desde los parámetros que nos permite adoptar la historiografía más reciente, la microhistoria o «historiografía postmoderna». En primer lugar, parto de una inevitable dimensión subjetiva, convencida de que la historia es también una «ciencia de la interpretación», posición a la que ha conducido la ruptura del objetivismo y de los planteamientos estructurales, llevada a cabo por el giro lingüístico y, en particular, por lo que se ha conocido como «deconstruccionismo». En segundo lugar, prefiero el enfoque individualista, que ha sido - y es cada vez más - un espacio reivindicado por los historiadores ${ }^{5}$. Un campo de aplicación idóneo es el denominado «individualismo metodológico», en cuya raíz norteamericana, sobre todo -no tanto en el caso italiano--, permite destacar el peso de la acción humana, «con el correlativo debilitamiento de la fuerza determinante (o simplemente operativa) de las estructuras» ${ }^{6}$.

Desde esta postura se puede intentar que prevalezca la realidad sobre el modelo. Para ello, el tratamiento metodológico basado en la sistematización debe ser entendido como un estudio sustantivo de casos y no como una acumulación numérica. Las investigaciones deben plantear la necesidad de seguir las estrategias individuales ${ }^{7}$, tratando que la prospección histórica en los documentos no descuide los silencios, las repeticiones, los engaños, las manifestaciones de percepción y sentimientos... - lo que en definitiva Bailyn llamaba

4 Por ejemplo ElLIOTT, John H. (1963): La España Imperial, 1469-1716, «Vicens-Vives», Barcelona, 1965; LYNCH, John (1965): España bajo los Austrias (2 vols.), «Península», Barcelona, 1970 1972; KAMEN, Henry (1983): Una saciedad confictiva. Espafia, 1469-1714, «Alianza», Madrid, 1984.

5 Como ha sefíalado ANDRÉs-GALLEGo, José (Recreacion del Humanismo-Desde la Historia. «Actas», Madrid, 1994, pp. 150-154), uel enfoque individualista -personal- ha de entenderse como categoría del conocimiento (...) conseguir que lo individual -personal- se constituya en el principal punto de referencia y contraste gnoseológico, entendiendo por tal el que, explícita o implícitamente, tiene todo historiador cuando valora y emplea los datos con que reconstruye la historiay.

6 HERNÁNDEZ SANDOICA, Elena: Los caminos de la Historia-Cuestiones de historiografía y método. «Síntesis», Madrid, 1995, p. 152.

7 HERNANDEZ SANDOICA, Elena: Los caminos de la Historia ... op. cit., p. 152. 
latent events ${ }^{8}$ - que carecen de importancia en apariencia, pero que en realidad son indicios de la intencionalidad del sujeto, por lo que constituyen pistas valiosas desde el campo de la interpretación.

La historia de la familia, pues, ha venido haciéndose, en términos generales, desde parámetros poco coherentes con un humanismo integral, auténtico. Se ha desarrollado casi de forma exclusiva desde una óptica de relación entre coyuntura, ciclo vital, estrategia, movilidad social, reglas de herencia, mercado e ideología del sistema social dominante. Pero se han dejado a un lado cuestiones tan importante como son el amor, la amistad o cualquier otro tipo de sentimientos, y pienso que los parámetros historiográficos actuales reivindican -a gritos- la presencia de estas últimas variables, aunque no deban perderse de vista aquellas otras. En realidad, ambas son perfectamente conciliables dentro de una síntesis coherente y abierta.

\section{LA SOCIEDAD MODERNA}

En las sociedades preindustriales la familia era una manera de subsistir; sus formas predominaban en las estructuras organizativas artesanas y empresariales - prevalecían el taller familiar y el trabajo doméstico-, entre otras cosas porque la propia economía tampoco exigía más. El traspaso de los bienes se llevaba a cabo, en gran medida, mediante la dote y los sistemas de herencia, esto es, por cauces relacionados con la familia. Ésta desempeñaba un papel de primera importancia en el mantenimiento de un orden social cuya jerarquía parece depender, entre otros principios, del respeto hacia los mayores y los antepasados. Por todo esto - y mucho más que no señalo, ya que es conocido por todos-, la familia goz6 de una importancia singular durante la época moderna: es la célula inicial de la sociedad, y la constitución de ésta, incluida su naturaleza política, es una proyección analógica de la relación familiar. Esta conclusión de la filosofía perenne se percibe con claridad en las obras del momento: la familia se entiende como el pilar básico del Estado Moderno o, si se prefiere, el Estado como una suma de familias, correspondiendo a la autoridad del monarca su justo gobierno como al cabeza de familia el del grupo doméstico ${ }^{9}$.

8 BALYN, Bernard: «The Challenge of Modern Historiography», AHR, 86 (1981), pp. 1-23.

9 Así lo entendía Tomás MORO, llegando a considerar incluso el conjunto de la república como una familia a gran escala (Utopta -Basilea, 1518-. Ed. de P. RODRfGUEZ SANTIDRIÁN, «Alianza», Madrid, 1988, p. 136). Recoge la misma idea Jean BODIN (Los seis libros de la República -París, 1576-. Ed. de P. BRAvo GaLA, «Tecnos», Madrid, 1985, lib. I, caps. I y II, pp. 9-19). Además, dice el magistrado francés que al igual que «la administración doméstica es el recto gobiemo de varias personas y de lo que les es propio, bajo la obediencia de un cabeza de familia», la «República es un recto gobiemo de varias familias, y de lo que les es comán, con poder soberano». En este sentido, la

Hispania, del Mediterráneo al Atlántico Hispania Sacra 51 (1999) 
Una prueba entre otras de la importancia que se le atribuye en la España del siglo XVII lo constituye que tratados y memoriales del momento denunciaran las desviaciones sexuales en número creciente, y otras alteraciones en la farnilia, como causa de la «declinación» de la monarquía hispana. De este modo, por ejemplo, el licenciado Martín González de Cellorigo creyó observar el origen de la despoblación en una conducta de desmoronamiento moral de la sociedad $^{10}$. En su opinión, más que factores de otra índole -enfermedades, guerras, ciclos de hambruna, etc.--, habría sido la desestimación de la familia lo que más habría redundado en perjuicio de la «abundancia de gentes» en los reinos peninsulares. Consideraba que aquellos factores sencillamente se habrían plantado sobre un terreno previamente abonado por la preferencia de la soltería - no del celibato religioso, aunque algunas interpretaciones posteriores lo incluyan- en detrimento del matrimonio. Según él, a esto habría contribuido la permisiva dinámica social de su tiempo, en la que el amancebamiento y el adulterio, entre otros, permanecían inmunes o con escaso castigo. Este rechazo a la vida marital - nos dice- suponía un daño a la procreación, puesto que se procuraba que no nacieran hijos de las relaciones extraconyugales -anticoncepción- 0 , cuando nacían, se desamparaban a la puerta de los templos expositos- para evitar la reprobación de la sociedad ${ }^{11}$. Sigue comentando que la ostentación y el lujo en los hábitos de las mujeres - ya sabemos que lógicamente estaban en el centro de la voragine- y la importancia social atribuida a las dotes eran otros tantos factores que perjudicaban al matrimonio.

No sólo Cellorigo, también Tomás de Mercado, Sancho de Moncada, Pedro Fernández de Navarrete, Miguel Caxa de Lenuela, Saavedra Fajardo y otros vieron como orígen de todos los males el desmoronamiento moral de la socie-

familia *constituye la verdadera fuente y origen de toda república, ast como su principal elemento (...) Al igual que la familia bien dirigida es la verdadera imagen de la república, y el poder doméstico es comparable al poder soberano, asi, el recto gobierno de la casa es el verdadero modelo del gobiemo de la repúblican.

10 GonzÁlez de Cellorigo, Martín (Valladolid, 1600): Memorial de la politica necesaria y útil restauración a la república de España y estados de ella, y del desempeño universal de estos reinos. EÁ. de J.L. PÉREZ DE AYALA, «Instituto de Estudios Fiscales», Madrid, 1991, pp. 58B65. González de Cellorigo mantiene el misino concepto sobre la «república», sin duda por influencia del magistrado francés Jean Bodin.

11 Es cierto que la fuerza de la censura social tal vez pudiera estar por encima de otros lazos, como los familiares, situando ciertos códigos de comportamiento sobre determinados sentimientos afectivos -la maternidad, por ejemplo- en tales casos. Pero no cabe plantear la cuestión exclusivamente ast, como veremos a continuación; por el contrario, recordemos de momento con STONE, Lawrence (Familia, sexo y matrimonio en Inglaterra, 1500-1700 -Londres, 1977, ed. abreviada en 1979-, «Fondo de Cultura Económica», México, 1990, pp. 45-54) que la elevada tasa de mortalidad infantil tendría consecuencias en la actitud de los padres hacia sus hijos, en el sentido de limitar -por propia estabilidad mental- el grado de relación psicológica con ellos.

Hispania, del Mediterráneo al Atlantico Hispania Sacra 51 (1999) 
dad que tenía su principio en el de la familia. No se limitaron a apreciar los trastornos en los precios, las oscilaciones de la moneda, las carestías o los desasatres militares. También consideraron las alteraciones en la familia como causa de despoblación, los vagabundos y grupos marginados, las desviaciones sexuales en número creciente, las epidemias y su incidencia social -no sólo demográfica一, etc. ${ }^{12}$

En este sentido, para una comprensión cabal del contenido de sus obras aunque se trate de doctrinas económicas (o pre-económicas, si se prefiere) en algunos casos - es preciso relacionar su concepto de decadencia con el sistema filosofico de todos aquellos autores -el catolicismo- al cual nos remiten insistentemente. Esto es, a los fundamentos antropológicos que constituían sus concepciones y posiciones respectivas sobre el ser humano y cuanto lo rodeaba. La defensa de la vida familiar, la caridad, la tolerancia, la solidaridad, las formas de sociabilidad, la vida cotidiana, los modos de pensamiento, las actitudes ante la muerte, etc. se convierten así en elementos de juicio indispensables en cualquier análisis sobre sus ideas, aún cuando este análisis pretenda ser exclusivamente económico. Como diráa Bennassar «lo económico no es suficiente para explicar lo económicos ${ }^{13}$.

Tal vez ahora sea posible afirmar que las derrotas militares, la revolución de los precios, las oscilaciones del vellón, la escasez productiva, etc. carecen de importancia como tales. Importan porque marcaron gravemente a los hombres que las vivieron. Por este camino lograremos ver la decadencia no s6́lo como una evolución negativa de variables empíricas, sino como un sentimiento desgarrador en la conciencia humana. No una simple constatación y si un desgarramiento existencial en las vivencias cotidianas de las gentes.

La mentalidad de la época culpó particularmente a la mujer —una vez más- del bajo índice de matrimonios. Y este tema, cierto o no, se consideró como la causa inmediata del problema de la despoblación. Cellorigo denuncia$\mathrm{ba}$, como he apuntado en parte antes, que la verdadera catástrofe de su tiempo era la preferencia de la soltería en detrimento del «fruto virtuoso del matrimonio, con que se fertilizar nuestra República de buena gente, habida y procreada de légitimos y honrados padres (...) huyendo del matrimonio desamparan la procreación y dan en extremos viciosos (...) de donde si salen hijos ni son criados ni sustentados y ast se hace falta al aumento de la República ${ }^{14}$. Merece la pena, pues, que analicemos este tema con algo más de detenimiento.

12 Veáse la Memoria de Licenciatura de M. J. Cañada Homos, Pensamiento económico en la España Moderna: las denuncias sociales en torno al sentimiento de "declinación». Jaén, 1997. Inédita.

13 Origenes del atraso económico español. Siglos XVI-XIX. Barcelona, Ariel, 1985, p. 147.

14 M. González de Cellorigo, Memorial de la Polffica necesaria ..., op. cit., p. 58. 


\section{LA DOCTRINA CATOLICA SOBRE EL MATRIMONIO}

En la época moderna, es probable que España estuviera próxima al modelo occidental en lo que se refiere a una elevada proporción del celibato ${ }^{15}$. Su alarmante extensión explica que fuera denunciado por los arbitristas e ilustrados una vez tras otra, por considerarlo un auténtico lastre demográfico y social. De hecho la ofensiva a favor del matrimonio, que había dado comienzo con los erasmistas y fue continuada después, como veremos, por los téblogos contrarreformistas, obedecía a un paulatino desprestigio de la vida matrimonial y a la paralela exaltación idealizada de la «soltería feliz» masculina.

La doctrina de la sacramentalidad del matrimonio, implícita durante el primer milenio, fue abriéndose paso a partir del siglo XII en la Teología - Anselmo de Laón, Hugo de San Victor y santo Tomás de Aquino que la sistematizo- así como en los documentos oficiales - II concilio de Letrán (1139); sínodo de Verona (1184); profesión de fe de Inocencio III (1208); II concilio de Lyon (1274)-. El decreto para los armenios del concilio de Florencia (1439) definía el matrimonio como el séptimo de los sacramentos, signo de la unión entre Cristo y la Iglesia. Y finalmente, puesto que Lutero y los protestantes la habían impugnado, el concilio de Trento ratificó dicha sacramentalidad en el célebre tratado Tametsi.

Además de debatir y probar doctrinalmente el carácter sacramental del matrimonio, también se definió pastoralmente su validez cuando se celebra ante un sacerdote competente y dos testigos como mínimo, y su clandestinidad en caso contrario. Se acordaron asimismo definitivamente otras cuestiones que tampoco habían estado claras en la época precedente: rechazo de la poligamia, principio de indisolubilidad y facultad de la Iglesia para señalar otros impedimentos.

Desde finales del siglo XVI, las reformas tridentinas tuvieron que ser asimiladas por cada diócesis, en primer lugar, y compendiadas generalmente en pequeños códigos - constituciones sinodales- cuya elaboración y promulgación se produjeron lentamente a lo largo del siglo XVII e incluso del XVIII' ${ }^{16}$.

La cuestión es que para la mentalidad de la época que nos ocupa, determinadas actividades de la vida doméstica o familiar sólo podían llevarse a cabo después de haber contraído lo que entonces la moral ya consideraba como un vínculo indisoluble. No era cuestión exclusiva de una relación sexual ilícita —aun-

is V. Pérez Moreda, «Matrimonio y familia. Algunas consideraciones sobre el modelo matrimonial español en la Edad Modernas, en Boletin de la Asociación de Demografia Histórica, 4,(1986), p. 3-51.

16 Constituciones Sinodales del Obispado de Jaén, hechas y ordenadas por el llmo. Sr. D. Baltasar de Moscoso y Sandoval, cardenal de la Santa Iglesia de Roma, obispo de jaén, del consejo de su Majestad, en la sinodo diocesana que se celebró en la ciudad de Jaén en el año de 1624. Jaén, 20 impresión por Pedro Joseph de Doblas, 1787. Ejemplar conservado en la Biblioteca del AHDJ. 
que ésta fuera un tema de preocupación específica-, sino de la frecuencia de cualquier acto de convivencia: visita, trato, comunicación, etc., que denotara una intimidad más allá de los límites aceptados socialmente ${ }^{17}$. $\mathrm{Y}$ es que entre las concepciones al uso, el matrimonio se entendía como el único espacio social capaz de conceder por sus efectos sacramentales sobre el individuo, el auxilio necesario para sobrellevar las posibles cargas que derivaran de la unión conyugal y de la obligación de «vivir juntos, asistirse, obsequiarse, seguirse y criar los hijos con buena educación» ${ }^{18}$. En definitiva, toda familia tenía su orígen en el matrimonio.

De acuerdo con lo dicho, sirva como ejemplo la acusación hecha en 1629 contra el licenciado Francisco Ortiz, clérigo de menores y vecino de la villa giennense de $\mathrm{Jódar}^{19}$. Se le culpaba de amancebamiento, durante sus estudios en la Universidad de Baeza, con Isabel de Montanos, mujer soltera de diecinueve años y vecina de esta ciudad. La acusación no se dirigía sólo contra una relación sexual; también hacía referencia a determinadas costumbres que estaban restringidas estrictamente al ámbito familiar: «comiendo y durmiendo juntos, como si fueran marido y muger, entrando y saliendo en su casa de dia y de noche y a todas horas». Asimismo, se denunciaba que Francisco Ortiz había enviado la comida y la cena a casa de la acusada con un criado en repetidas ocasiones, y que otras muchas había acudido personalmente, "con tanta libertad como si estuvieran casados (...), a comer, cenar, lavarse y aderezarse y lavar su ropa blanca». Los testigos del caso - -ntre quienes se encontraban personas que habían vivido en la misma casa- declararon cómo Ana Cárdenas, madre de la acusada, había tenido conocimiento de todo este asunto, puesto que ambas mujeres «le guisan, le laban y enjabonan».

Hacia el siglo XIII se habían logrado defender los principios de monogamia e indisolubilidad, precisar y prohibir el incesto, castigar la fornicación y el adulterio y hacer que los bastardos estuvieran excluidos legalmente de la herencia de propiedades. Pese a todo, aún faltaba una definición contundente

17 En el siglo XVIII la Iglesia todavía advertía de los peligros inherentes a que los novios pudieran verse o visitarse en sus casas mientras duraban las admoniciones públicas. Archivo Diocesano de Cáceres, Libro de visitas, Riolobos, leg. 15, fs. 289-304, ax̂o 1736. Cit. por A. Rodríguez Sánchez en «El poder y la familia. Formas de control y de consaguinidad en la Extremadura de los tiempos modernosm, en Poder, familia y consaguinidad en la Espafia del Antiguo Regimen, Barcelona, Anthropos. 1992.

18 Veáse fray Francisco de Larraga: Promptuario de la Theologia Moral muy util para todos los que se han de exponer de confessores, y para la debida administracion de el Sancto Sacramento de la Penitencia. Madrid, 350 impresión por Herederos de Juan García Infanzón, 1757. Ejemplar conservado en el AHDJ. Tratado IX: De el Sacramento del Matrimonio, f. 102.

19 AHDJ, Criminales, leg. 56-A, doc.1. 
sobre el matrimonio. Prácticas como la barraganía y los matrimonios clandestinos mantenían una extensión considerable.

Hubo de ser en el concilio de Trento, como acabo de señalar, donde se estableciera la forma definitiva del matrimonio, proclamando su efectividad como recepción de un sacramento cuyo vínculo significa la unión entre Cristo y su Iglesia. Hay quien ha definido esta sacramentalización del matrimonio como la institucionalización de una doble práctica del consentimiento ${ }^{20}$. En primer lugar de carácter social: 1) el de los contrayentes, que acudían libres y por su propia voluntad --básico para el principio de indisolubilidad-; y 2) el de la sociedad, padres de los conyuges incluidos, cuyo consentimiento tácito se demostraba por la falta de impedimentos en las admoniciones públicas. En segundo lugar, el de la Iglesia, que a partir de 1563 sólo legitimaría la cohabitación de los esposos - no śblo la consumación, sino también el compartir casa, mesa y cama, como ya se ha dicho- si la celebración matrimonial había gozado de las bendiciones «in facie Ecclesiae», empleando la expresión de la época. Esto es, el matrimonio era tenido por válido cuando --además de otros términos- hubieran estado presentes un sacerdote y al menos dos testigos, y se hubiera recibido integramente en sus dos tiempos: boda y velación.

Desde finales del siglo XVI el matrimonio quedó institucionalmente bien definido, por tanto. Las constituciones giennenses de 1624 establecían con toda claridad que los párrocos tenían el deber de estar presentes en la celebración de los matrimonios con la autoridad y decencia debida, no como ministros, porque éstos eran los propios contrayentes, sino como testigos de la Iglesia. Asimismo los facultaba para conceder licencia a otro sacerdote que, en su nombre, asistiera a un matrimonio en su parroquia, no siendo válido en caso contrario $^{21}$. Sin embargo, entre los individuos aún había formas marginales de concebir algo que, a fin de cuentas, enraizaba con las costumbres de su existencia cotidiana. El sínodo diocesano de Jaén denunciaba el asunto con las siguientes palabras:

«Los matrimonios clandestinos siempre han sido prohibidos, y odiosos en la Iglesia; y advirtiendo el santo concilio de Trento que las cautelas, remedios del derecho no bastaban a impedirlos, antes cada dia crecía más la inobediencia, ordenó próvidamente nuevas prohibiciones, y penas, que en parte han atajado el mal, pero no en todo, como la

20 A. Rodríguez Śnchez, «El pader familiar...», op. cit., pag 369-370. En mi opinión la exclusividad con que el autor presenta esta cuestion desde aspectos puramente sociales relega cuantas aportaciones se debieron al progreso en la doctrina eclesiástica, ignorando el importante papel que ésta representó en la evolución del matrimonio en particular, y de la familia en general.

2I CSJ, I, VIII, cap. VIII, fol. 22. 
experiencia enseña (.....); y declaramos propriamente clandestino, el que se contrae sin parroco o testigos; e impropriamente el que se hace sin las amonestaciones de la Iglesias 22.

\section{... HAY QUE SALVAR LA HONRA: LA PALABRA DADA}

El incumplimiento de la palabra dada y la burla hacia la persona que había confiado en ella, obtuvo un puesto notable en la Literatura de nuestro Siglo de Oro. Frecuentemente se trataba de una mujer cuya posesión carnal era solicitada por algún cortejador. En el siglo XVI, la idealización del amor - patrocinada por el neoplatonismo de orígen italiano- se vio enfrentada progresivamente con las exigencias morales y sociales de la vida cotidiana. Sobre todo después del concilio de Trento, cuando la Iglesia se preocupó por imbuir a la Literatura de los valores religiosos acordes con sus exigencias. Nuestros escritores retomaron entonces las críticas que ya a comienzos de la centuria habían formulado humanistas como Luis Vives y Juan de Valdés contra los libros de caballerías, por retratar situaciones ajenas a la naturaleza y experiencia humanas. Abogaban por sustituir esa literatura por otra mas «verdadera», capaz de reflejar una visión cristiana de la vida y un sentido de responsabilidad ante los deberes sociales y las obligaciones morales, sin falsos idealismos ${ }^{23}$.

Lo cierto es que el argumento de la palabra incumplida halló un cauce propicio en nuestra literatura porque, si descendemos desde la ficción hasta la realidad documental, las cosas parecen cambiar poco. En la documentación abundan los casos en que se impide, y hasta se procesa al causante, por este motivo. La movilidad geográfica de los sujetos fue sin duda un aliado favorable para mantener una conducta desordenada. En este sentido, el control que finalmente se establecería sobre el matrimonio de los soldados pudo estar relacionado con ello. Es el caso de Francisco Gómez, quien había dado «palabra de casamiento» en Baeza a Magdalena de Agueda y después ésta tuvo que demandarlo en Jaén porque se quería casar con Rosalía Torralvo, vecina de esta ciudad ${ }^{24}$.

Sin embargo, procuremos no caer en el anacronismo. En este tiempo ya nunca se identificó el matrimonio con la promesa de contraerlo. Hemos visto cómo aquél ya estaba perfectamente definido. En todos los casos como el de Francisco Gómez siempre se da por sabido que el matrimonio sólo es efectivo

22 Ibid., I, VIII, cap. IX, f. 23. La prohibición de la Iglesia procedía de que algunos se casaban clandestine con una e in facie Ecclesiae con otra, con el perjuicio consecuente para los tres.

23 Veáse A. Parker, La filosofía del amor en la Literatura española, 1480.1680. Madrid, Cátedra, 1986, pp.127 y ss.

24 AHDJ, matrimoniales-pleitos, leg. 535-A, doc. 2.

Hispania, del Mediterráneo al Atlántico

Hispania Sacra 51 (1999) 
"según horden de la Santa Madre Yglesia» o «en faz de la Santa Madre Yglesia», ambas fórmulas aparecen en todos los documentos consultados. Lo cual no impide que se conceda cierto carácter vinculante a la palabra otorgada antes de recibir el sacramento, y la justicia se encargó de que así fuera ${ }^{25}$.

En realidad, el concepto de matrimonio clandestino, celebrado en secreto sólo por los contrayentes y tal como se había entendido en épocas anteriores, ha desaparecido en la España de los siglos XVII y XVIII. Más bien parece quedar sólo un residuo de aquél, referido a la consumación sexual del compromiso. A veces servía como cierto «pretexto moral» para mantener una relación al margen del matrimonio, no legitimada por el conjunto de la sociedad y, en consecuencia, tampoco exenta de cautelas para encubrir su furtividad. En el caso ya mencionado de Isabel Montanos ${ }^{26}$, al año de haber sido abierto el expediente comparecí la joven acusada, que declaró conocer al licenciado Ortiz desde hacía tres años, aunque sólo llevaban uno con relación carnal y previo trato «debaxo de palabra de casamyento». Los testigos en el auto sabían de seguro que había nacido una criatura de aquella relación cuyo destino último desconocían, aunque la joven había intentado engañarlos diciendo que padecía "otro achaque para disimular el parto». Finalmente ésta reconoció ante la justicia el alumbramiento de una niña, a la que llamaron Francisca, y que «crió a sus pechos» la madre del acusado. Aproximadamente un año después, cuando todo hubo sido descubierto y la pequeña estuvo «destetada», la recogió en su propia casa.

Otras veces no aparece esa extensión en el tiempo como característica de la relación entre el hombre y la mujer. Había individuos que, con la pretensión de mantener un episodio sexual fortuito, otorgaban su palabra de hacerlo estable en el futuro sólo para vencer la voluntad de la pareja en aquel instante. No era infrecuente olvidar todo después, aunque en muchas de esas relaciones la mujer quedaba embarazada.

En parte ya apuntaba más arriba que un nutrido número de la muestras - tanto documentales como literarias- que podemos obtener sobre la palabra dada en la época hacen referencia a estos casos. Frente a esta eventualidad y sus implicaciones sociales, la mujer «burlada» sólo podía recurrir a la justicia tratando de obligar el cumplimiento de la promesa. Para ello debía presentar una querella por estupro contra el «autor de su deshonra», mientras que la suerte de obtener una sentencia favorable en el pleito dependía de la existencia de testigos, lo cual no sería fácil porque lógicamente la concesión de palabra —de haber llegado a término- se habría hecho en la más absoluta intimidad. No

25 AHDJ, matrimoniales-pleitos, leg. 474-B, doc. 5.

26 AHDJ, criminales, leg. 56-A, doc.1. 
nos extrañe, por tanto, que abunde el testimonio de vecinos que corroboran la promesa por haber presenciado la escena a través de agujeros que, casualmente, horadaban los tabiques de medianería.

Así lo encontramos, por ejemplo, en el caso de Ana Teodora Pérez, quien presentó una denuncia ante la justicia eclesiástica contra Andrés Rodríguez, por haber incumplido éste su palabra de casamiento y por estupro. El maestro de sastre Bartolomé Velázquez y su esposa, así como otra mujer que había ido para contratar sus servicios, testificaron que vieron todo lo ocurrido a través de un agujero existente en el tabique que mediaba entre su casa y la casa de la demandante, y al cual se asomaron «llebados de la curiosidad y por el ruido que oyeron por causa de la dicha fuerza y biolenzia». La autoridad comprobó la existencia de este orificio en la pared.

El caso originó un abultado expediente, debido al rumbo que las cosas adoptaron conforme se hacían los autos, por cuya causa es muy interesante para considerar varias cuestiones. La denuncia de Ana Teodora Pérez se fundaba en los siguientes términos:

«vibiendo con Melchora de Medina, su madre, a espaldas de las casas obispales, el dicho Andrés Rodríguez la solizitó y galanteó, haziendo diferentes asistenzias en la calle con mucha nota y escandalo y handando de dia y de noche por las esquinas y ablando con mi parte (...) Estando vibiendo con toda onestidad y recato, como donzella onesta y recojida, en el dia domingo de carnestolendas del año pasado de mil y seiscientos y nobenta y uno, hallandose sola por aber salido la dicha su madre, el dicho Andres Rodriguez se arrojó a las casas de mi parte, y entró en ellas con animo de forzarla y estruparla. En que abiendo entrado y quiriendo conseguir su boluntad de gozarla, enpezó a forzejear y a bregar con ella, a que se resistió mi parte todo lo posible, defendiendose del dicho reo, diziendole que como queria hazer una cosa como esa con mi parte, siendo donzella; a que le replicó que porque se abia de casar con ella; a que le dixo le diese palabra de casamiento y mano con testigos; a que replicó dicho reo que si abia de yr a la calle a buscar testigos para ello, que el le dava palabra de casamiento y mano como con efecto se la dio, y que Jesus Nazareno y la Virjen del Rosario le dava por testigos. Y con esto abiendole dado la mano, la echó enzima de la cama, y la gozó y ubo su birjinidad ${ }^{27}$.

Andrés Rodríguez trabajaba como veedor y medidor de las tierras de la catedral, en cuya obra se ocupaba también como cantero. Cuando hubo sido en-

27 Ibid., fs 27-28.

Hispania, del Mediterráneo al Atlántico Hispania Sacra 51 (1999) 
carcelado trató de sobornar a dos testigos con sendos doblones si declaraban en su favor, diciendo que el dia señalado habían salido al campo en su compañía por cuestiones de trabajo. Creyó poder hacerlo porque sus oficios eran comunes. Se trata de Alonso Sánchez y Juan Verrio Saeta, ambos fieles de los bienes del campo de Jaen. Estos no aceptaron el soborno alegando en su testimonio que "primero era su alma que quantos doblones y tesoros avia en el mundo» ${ }^{28}$.

Fracasado, pues, en su primer intento, Andrés Rodríguez quiso entonces desacreditar a Ana Teodora Pérez mostrándola como una mujer liviana y calumniosa. Alegó que el hijo no era suyo, sino de Juan Fernández, lacayo y mozo de silla del obispo D. Juan Asensio, que a la muerte de éste se había marchado de Jaén. Esta vez sobornó con éxito a otros criados del palacio episcopal, quienes declararon ser cierto que la mujer había tratado con el lacayo, y que lo había responsabilizado de su embarazo en conversaciones mantenidas con él. El notario de la demandante trató de desçalificar estos testimonios comparando sus propios testigos, «personas muy honradas, y muy buenos christianos, temerosos de Dios y de su conzienzia», con los del acusado que, además de «falsarios tienen el defecto de ser lacayos, y jente vmilde y de baja esfera» ${ }^{29}$.

A esas alturas, el vecindario ya comentaba las circunstancias de la «desdichada Teodora» con una mezcla de burla, censura y compasión. En cualquier caso, aparecen expresiones que nos dan idea del ostracismo moral - la deshonra- en que se situaba a las mujeres cuando les ocurría esto, así como los dardos que debían soportar, privándoles sin duda de autoestima en los momentos que más la necesitaban.

Finalmente, la defensa de Andrés Rodríguez, en manos de don Antolín Gómez, interpuso una querella contra el notario público que había instruido el sumario, don Francisco Luis de Requena. Acusaba a éste de haber hecho los autos al margen de la legalidad, de haber cometido numerosos errores en el interrogatorio y de haber dado fe sobre aspectos de cuya veracidad no se había cerciorado -entre otros, los domicilios de algunos testigos - ${ }^{30}$. La sentencia resultó desfavorable para Ana Teodora Pérez, por considerar que ésta no había probado su demanda, y Andrés Rodríguez quedó en libertad. La mujer apeló, pero tras varios años tuvo que retirarse por falta de medios económicos para sostener el curso del pleito. Tiempo después trató de reabrir su causa ante la justicia civil.

\footnotetext{
28 Ibid., f.10.

29 AHDJ matrimoniales-pleitos, leg. 533-A, doc. 5.

30 Sobre el sistema judicial de la época y sus posibles discapacidades, veáse J. García Marín, $L a$ burocracia castellana bajo los Austrias. Sevilla, Instituto García Oviedo, 1976, pp. 126-146.
} 


\section{LOS IMPEDIMENTOS Y... EL AMOR}

Como se ha señalado ya, todos los expedientes matrimoniales consultados ofrecen, en primer lugar, las declaraciones de los contrayentes afirmando no tener impedimentos para casarse por voto de castidad $\mathbf{u}$ otro cualquiera de religión, ni por haber contraído esponsales con otra persona, ni por estar sujetos a excomunión, pecado y escándalo público. Se trata de los «impedimentos impedientes» ${ }^{31}$ en los cuales se incluye la falta de amonestaciones según lo dispuesto por el concilio de Trento. Al margen de éstos estaban los «impedimentos dirimentes», que también ocuparán nuestra atención más adelante.

Por conditio se entendía una condición establecida antes de contraer matrimonio en contra de cualquiera de sus tres bienes - bonum prolis, bonum fidei y bonum sacramenti -32 . Otro de ellos era el parentesco o cognatio. Podía ser espiritual en el caso de los padrinos de bautismo y confirmación, o legal, es decir, el que se contraía con alguna persona adoptada en la familia. Éstos no podían contraer matrimonio con sus ahijados.

Pero el verdadero significado en la época es el parentesco natural, objeto además de la mayoría de trabajos que optan por estudiar la familia como reproducción del sistema social, establecimiento de alianzas de poder, etc. ya enumerados al principio de este artículo. Se entendían dos líneas de cognatio natural: 1) recta, es decir, de padres a hijos; 2) transversal, que engloba a hermanos, primos carnales, primos segundos y terceros, hasta el cuarto grado inclusive. Para conocer los grados de consanguinidad, «se han de contar las personas que hay, descontando una que es el tronco» ${ }^{33}$. El impedimento de parentesco podía salvarse pidiendo una dispensa.

En el caso de familias pertenecientes a los estratos sociales más elevados, el matrimonio entre parientes pudo constituir -no siempre sería así- un instrumento al sevicio de objetivos como la conservación y acumulación de propiedades, la formación de alianzas políticas, etc. Sin embargo, en los lugares de población reducida la razón parece haber sido más bien una endogamia geográfica ${ }^{34}$. Puesto que los efectivos demográficos son escasos, para cualquier hombre o mujer resultaría difícil encontrat con quien contraer matrimonio sin que hubiera algún lazo de consaguinidad por medio. Uno de los ejem-

\footnotetext{
31 Fray Francisco Larraga, Promptuario..., tratado IX: «Del Sacramento del matrimonio», f.113.

32 Ibid., f. 115.

33 Ibid., f.117.

34 Estamos de acuerdo en lo esencial con E. Garrido Arce quien lo mantiene para la zona valenciana en su artículo «Fanilia, parentesco y alianza en la muerte de Valencia, siglo XVII. La estrategia familiar de la consanguinidad» en Estudis, 18, pp. 217-238.
} 
plos más representativos de la provincia de Jaén puede ser $\mathrm{Ibros}^{35}$, donde he podido comprobar bastantes casos de parentesco en cuarto grado.

Muchos documentos de Ibros reflejan que los contrayentes son tan pobres que ni siquiera pueden pagar los gastos de la dispensa. Esta se les concede mediante un "pago espiritual», consistente en algunos actos de penitencia y devoción. También se hace constancia de que la dispensa es necesaria debido a los pocos habitantes, puesto que si los parientes no se casaran entre ellos no encontrarían otra persona con quien contraer matrimonio. Los contrayentes declaran abiertamente que no conocen a ningún hombre o mujer de.la villa con quien no tengan algún lazo de consanguinidad.

Otro impedimento dirimente era el error qualitatis, explicado por fray Fancisco Larraga en los siguientes términos:

«Pedro le dice a Juán, que si quiere casarse con su hija María, le dará mil ducados de dote; y Juan responde, que con essa condición se casará, y si no se los da, que no es su intención casarse con ella: cásase, y se halla que no tiene, ni le dan los mil ducados, es nulo el matrimonio» ${ }^{36}$.

Se explica así que en muchos expedientes se perciba como preocupación casi constante la igualdad social de los futuros esposos. Doña Luisa de Biedma y Pareja, veinticuatro años y vecina de Jaen, no había hallado «barón de su ygual calidad o estado y condiçion con quien poder casar», hasta que en 1631 lo hizo con su pariente - cuarto grado doblado- don Martín de Nicuesa Cobaleda, viudo con treinta y tres años y vecino de la misma ciudad ${ }^{37}$. Diferente parece el caso de otros dos parientes - tercer grado-, Pedro de la Muela y Melchora de Cobo (1622), entre quienes sucede que ésta «no tiene dote competente para poder cassar con persona de su ygual estado, calidad y condiçion» pero aquél «se contenta con la poca dote que tiene, y la quiere dotar de sus propios bienes y caudal conpetentemente ${ }^{38}$. En atencion al error qualitatis era importante clarificar esta cuestión antes de contraer el matrimonio.

Todo lo visto parece situarnos ante mecanismos que favorecían el matrimonio por conveniencia, cuya existencia es indudables. Sin embargo, desde otra perspectiva nos ayuda a comprender que sólo razones muy poderosas podían prevalecer por encima de estas disposiciones, como por ejemplo el amor sincero. De hecho, en la documentación consultada encontramos casos

35 AHDJ, matrimoniales-parientes, legs. 396-A y 396-B, años 1747-1794.

36 Ibid., f. 114

37 AHDJ, matrimoniales-parientes, leg 515-B, doc. 2.

38 AHDJ, matrimoniales-parientes, leg 515-B, doc. 4. 
muy significativos, suceptibles de ser interpretados como matrimonios por amor. A medida que avanzan los tiempos modernos, es previsible que su número, frente al condicionamiento de la igualdad social, se haya elevado, sobre todo si atendemos a la Pragmática del 23 de marzo de 1776.

Nos encontramos aquí ante otro de los puntos más controvertidos entre los investigadores: el amor ${ }^{39}$. Recurriendo al ejemplo más conocido y más empleado - a veces para generalizar-, el trágico final en la famosa historia de Romeo y Julieta, según la versión de Shakespeare, puede ser interpretado como el destino inexorable de quienes faltan a la obediencia paterna - Jack Goody ${ }^{40}$ - , o bien como prueba de que el amor era necesariamente imposible en la sociedad que ambienta la obra -Elisabeth Badinter ${ }^{41}$ - Sin embargo, la compleja interrelación temática de tensiones y oposiciones que compone este drama permite interpretar, en mi opinión, la importancia central del amor como elemento que ensalza las características de intensidad, mutua sumisión e idealismo que afectan a los dos protagonistas frente al realismo, convencionalismo o tono moral que inspira al resto de los personajes. En definitiva, un llamamiento de Shakespeare en los albores de una nueva época con la que quiere enfrentar la sociedad de su propio tiempo.

Matrimonios por amor pueden ser considerados prácticamente todos aquellos en los que resalta de alguna manera - a veces violenta - la oposición de los padres. De la obediencia a éstos podía depender la herencia futara allí donde los ordenamientos legales permitían al testador que dispusiera libremente de sus bienes ${ }^{42}$. Y sobre todo no debemos olvidar que el respeto y la obediencia a los padres - cuyo único freno debía ser la Ley de Dios- era la regla ética que a cada hombre y mujer se inculcaba dentro y fuera del respectivo hogar, especialmente desde que la catequesis tomó fuerza definitiva en las comunidades cristianas a partir del Quinientos ${ }^{43}$. De modo que raramente se faltaría al respeto a los padres si no era por razones muy importantes para el propio individuo, como por ejemplo el amor.

39 Para conpletar este tema puede consultarse María Antonia Bel Bravo, La mujer en la Historia, Madrid, Encuentro, 1998, pp. 89-93.

40 «Prologo» a André BURGUière y otros (dirs.) Historia de la familia, Madrid, Alianza, 1988, p. 10.

41 E. BADINTER, ¿Existe el instinto maternal?. Historia del amor maternal (siglos XVI al XX), Barcelona, Paidos, 1991, p. 35.

42 Al igual que la dote como posible coacción inicial, el testamento podía ser una pretensión perpetuadora de la parria potestad. Véase Ángel RODRíGUEZ SÁNCHEZ: «El poder familiar...», op. cit., pp. 365-380.

43 Véase José ANDRÉS-GALLEGo, Historia general de la gente poco importante. América y Europa hacia 1789, Madrid, Gredos, 1991, pp. 22-26, y Ricardo GARCiA-VILLOSLADA, Historia de la Iglesia, Madrid, BAC, 1980, tomo III-21, pp. 363-371.

Hispania, del Mediterráneo al Atlántico

Hispania Sacra 51 (1999) 
Un ejemplo evidente de oposición lo encontramos en Ana de Vega, vecina de Jaén, que en 1751 solicita permiso a sus tutores, don Juan de Seijas y doña María Isabel Vázquez, para casarse con Sebastián de Peralta, quienes no solo se lo niegan sino que se la llevan a Bailén prácticamente secuestrada ${ }^{44}$.

Mayor significado aún tiene la consulta que don Manuel de Mercado y doña Inés Hermoso efectuaron a las autoridades eclesiásticas del distrito episcopal de Jaén, en 1635, con el fín de cerciorarse sobre si podían o no casarse sólo por consentimiento mutuo ${ }^{45}$. Se enfrentaban a la oposición del padre y el hermano de la contrayente. Obtuvieron como respuesta que, no existiendo otros impedimentos sobre ambos para contraer un matrimonio canónico válido, éste no podía verse afectado por la oposición de nadie, ya estuviera dentro o fuera de la órbita familiar. Concluía el documento que la única autoridad que el padre y hermano podían tener sobre doña Inés era puramente moral y no efectiva jurídicamente ante ninguna instancia.

Este ejemplo nos informa una vez más de cómo la Iglesia primaba la libertad personal de los contrayentes. Como también lo hace en la querella que interpuso en 1690 Ana Lopez Billena contra su marido ${ }^{46}$. Junto con el impedimento de coacción, parte de su argumento también se basaba en el error qualitatis, aunque esta vez con un contenido más personal:

«estando mi parte bajo del dominio y patria potestad de Diego López de Billena su padre, y de Catalina de Almagro su madastra, en la billa de Martos donde mi parte es natural, la susodicha le daba muy mala bida, por lo qual, y para quitarla de su presencçia, trato de casar a mi parte con Juan de Escalona sin beberlo ni tener notiçia de su persona; (...) una noche la engañaron y la sacaron de las casas de su morada, siendo mi parte de treze años, y la llebaron con dichos engaños, y que era muy rico y galán siendo yncierto (...) y mi parte les decía: Más quiero perderme que no casarme con el dicho Juan de Escalona, que ostedes me an engañada, y el matrimonio a de ser boluntario y no por fuerça, como ostedes lo quieren'».

Finalmente aceptó casarse porque su padre no dejaba de amenazarla, a instancias y persuasiones de su madastra. Después de un año y medio llorando y dando muestras de disgusto, «y que no quería coabitar ni consumar el matrimonio», su marido intentó matarla. El matrimonio fue anulado.

44 AHDJ, sala IX, carpeta 879-C.

45 AHDJ, sala IX, carpeta 534-B.

46 AHDJ, matrimoniales-pleitos, leg 533-A doc. 4. 
Otro impedimento dirimente era el rapto. En mi opinión, constituye una muestra más de cómo los futuros esposos se enfrentaban en ocasiones con la oposición de sus progenitores, llegando al secuestro de la mujer para evitarla. En este caso, la simple formulación a los testigos de esta pregunta - "que no ha sido robada ni atemorizada por el susodicho (contrayente),- en los expedientes matrimoniales podría estar más próxima al "temor» eclesiástico de equivocarse contra la voluntad de los padres que al interés por preservar la libertad de la mujer.

El crimen -otro impedimento- tenía varias acepciones. La primera de ellas, que alguno de los cónyuges asesinara al otro para poder casarse con otra persona con la que hubiera cometido adulterio. Este matrimonio sería nulo. En segundo lugar, también sería nulo en caso de que un adúltero se casara con su amante a la muerte de su primera esposa si previamente hubiera pactado hacerlo así.

La edad en que los individuos accedían al matrimonio apenas plantearía problemas, puesto que desde mucho tiempo atrás estaban perfectamente establecidas. En Las Siete Partidas de Alfonso X se había dispuesto que siete años era la edad mínima para desposarse, tanto para hombres como para mujeres, naciendo a partir de entonces:

«tal embargo deste desposorio si se partiese en vida ó moriese alguno dellos, que ninguno dellos non podrie casar con los parientes del otro (...) Mas para casamiento facer ha menester que el varon sea de edat de catorce años et la muger de doce, et si ante deste tiempo se cassasen algunos, non serie casamiento mas desposajas, fueras ende si fuesen tan acercados a esta edat que fuesen ya guisados para poderse ayuntar camalmiente; ca la sabidoria ó el poder que han para esto facer, cumple la mengua de la edat ${ }^{47}$.

Esta disposición sobre la edad mínima para contraer matrimonio se mantenía en la época moderna: catorce años para el varón y doce años para la mujer. En caso de celebrarse antes de que los contrayentes tuvieran esa edad, dicho matrimonio sería nulo por «impedimento dirimente» ${ }^{48}$.

Ahora bien, en términos demográficos se ha afirmado que el modelo de matrimonio común en el Occidente europeo, desde finales de la Edad Media, se caracterizó por un aumento progresivo de la edad de los cónyuges para contraer las primeras nupcias. La divergencia española es evidente al llegar a

47 Las Siete Partidas, partida IV, tít. I, ley IV: De qué edat deben ser los que se desposan».

48 Fray Francisco LARRAGa, Promptuario..., f. 123. 
este punto: durante la época moderna, la edad media de los varones al llegar al matrimonio era aproximadamente de veinticuatro años y la de las mujeres oscilaba entre los veinte y los veintidós ${ }^{49}$. Lo cual equivale a cuatro o cinco años más jovenes que sus coetáneos en el norte de Europa.

A la vista de algunas de mis propias consultas documentales, estas cifras requieren una matización mayor, al menos para el caso de Jaén. La edad de los varones coinciden en la mayoría de los casos. Así, por ejemplo, Blas Díaz contrajo matrimonio con Isabel de la Muela cuando aquél tenía veinticuatro años ${ }^{50}$, e igual edad tenía Francisco Jurado cuando Águeda Rodríguez de Guzmán se cas 6 en segunda nupcias con $e^{51}$, Por supuesto hay excepciones: Alonso Gutiérrez contrajo su matrimonio con María de la Paz a la edad de diecisiete años, cuando ésta contaba con poco más de trece o catorce años ${ }^{52}$. Precisamente es en la edad de las mujeres donde, como acabamos de apreciar, existe un marcado desajuste. Ana López Billena fue obligada a casarse por su padre y madrastra también a los trece años ${ }^{53}$. Salvo excepciones, las edades más tardías oscilan entre los diecinueve y veinte años. Por ejemplo Amador Chamorro, viudo de Flora de la Torre, contrajo segundas nupcias con Maria de Martos cuando ésta tenía diecinueve años de edad ${ }^{54}$.

Poligamia, orden sacro y ligamen —que ya suponian el establecimiento de un compromiso, el primero con Dios, y el segundo por estar casado con otra persona--, diferencia de credo, honestidad para con la familia política, impotencia perpetua, etc. componen el cuadro de los «impedimentos dirimentes».

\section{MUJER, FAMILIA, EDUCACIÓN}

Dentro de lo que ya sabemos sobre la familia en la España del Antiguo Régimen, donde nuestra visión se difumina más quizás sea en el ámbito de la vida privada y de lo cotidiano. Y es aquí, en cambio, donde el estudio de las cuestiones consideradas a lo largo de este trabajo cobra pleno sentido y adquiere relevancia. No debemos olvidar que en los siglos XVII y XVIII, al fin y al cabo, ś́lo dentro del ámbito famjliar, en lo privado y lo doméstico, tenían un espacio propio - salvo algunas excepciones - la condición femenina, la vida conyugal y otros aspectos que veremos a continuación, como el grado de

\footnotetext{
49 Véase Vicente PÉREZ MOREDA, «Matrimonio y familia...» op. cit,. pp. 3-51.

50 AHDJ, matrimoniales-ordinarios, leg. 449-A, doc. 2, aйo 1680.

51 AHDJ, matrimoniales-ordinarios, leg, 448-C, doc. 33, año 1679.

52 AHDJ, matrimoniales-ordinarios, leg. 449-A, doc 3, auro 1680.

53 AHDJ, matrimoniales-pleitos, leg 553-A, doc. 4, año 1690.

54 AHDJ, matrimoniales-ordinarios, leg 449-A, doc 1, año 1680.
} 
atención de los padres hacia su prole, la preocupación por la salud, su educación o su futuro, etc. Temas durante tanto tiempo olvidados por la «Gran Historia».

En virtud de ello, el análisis de algunos aspectos relacionados con ese transcurrir diario de la familia debe aproximarnos al conocimiento de cómo se estrecha la vinculación afectiva de sus miembros. Análisis éste que conecta a la historia de la familia con aquel otro descubrimiento temático de las últimas décadas: la historia de la vida cotidiana.

El hogar primero, y la comunidad de habitantes después, constituían los dos círculos primarios de sociabilidad en los que se desarrollaba la mayor parte de la vida de los hombres y mujeres de la época. En ambos espacios se irán llenando las horas y los días: individuos que comen, se visten, trabajan, se divierten, etc. Por supuesto que no trataré de abarcar estos temas en toda su complejidad. Cada uno de ellos requeriría, por sí sólo, un desarrollo mucho más extenso que el presentado aquí. Pero, a mi juicio, vale la pena sentar algunas directrices.

En pleno siglo XVII la filosofía y la teología manifiestan todavía —segín Badinter ${ }^{55}$ - un verdadero miedo a la infancia. Piensa esta autora que es porque la teología cristiana elaboró a través de la persona de San Agustín una imagen dramática del niño. «En cuanto nace, el niño es símbolo de la fuerza del mal, es un ser imperfecto, agobiado por el peso del pecado originals. San Agustín en La ciudad de Dios, describe a la criatura humana como un ser ignorante, apasionado y caprichoso, pero la idea del obispo de Hipona no está centrada, de forma única, en el pecado original sino en la imperfecta o ineducada naturaleza de la criatura, mientras que Badinter siguiendo a su vez a G. Synder, creyentes convencidos de la corrupción original - naturaleza corrompida protestante, no naturaleza dañada católica - hacen una interpretación reduccionista del tema. Por otra parte, no es exclusivo del pensamiento de San Agustín el uso de la dureza en los métodos educativos, sino que ésta es moneda de cambio en la época que nos ocupa.

Cuando empleo los términos derivados de «educar» no hago mera referencia a una transmisión de conocimientos sin más; también, aun abarcando esto último, a toda la complejidad y amplitud de la socialización primaria, a la cultura, en definitiva, que depende incuestionable de la situación familiar y, sobre todo, de la mujer como madre. De la misma manera que en otros lugares he tratado de estudiar su conexión con la vida ${ }^{56}$, ahora conviene no olvidar que esa conexión se prolonga en su labor educadora. La mujer no se limita a una

35 Op. Cit., pp 39-47.

56 Veáse María Antonia Bel Bravo, «Mujer y vida» en Anuario del Seminario Permanente de Derechos Humanos de la Universidad de Jaen, II, 1995, pp. 207-219.

Hispania, del Mediterráneo al Atlántico

Hispania Sacra 51 (1999) 
función procreadora y de crianza. $Y$ no lo hace porque no quiere, aunque $\mathrm{Ba}$ dinter $^{57}$ atribuya esta dimensión educadora de la mujer a una «injusta» ampliación de responsabilidades llevada a cabo en el siglo XIX, bajo la tutela de algunos pensadores.

En línea con esa inteligencia poliédrica que ya he defendido en otras ocasiones $^{58}$ como propia de la mujer, es necesario distinguir entre instrucción y cultura, porque la labor educadora de la mujer en la Edad Moderna más que en instruir consistió en «cultivar». Una educación que tiene más relación con la cultura que con la instrucción.

Naturalmente, toda cultura implica necesariamente un mínimo de instrucción, pero no ocurre lo mismo a la inversa: puede existir,y existe de hecho, instrucción sin cultura. La instrucción tiene más bien un caracter acumulativo y externo. Es una acumulación de conocimientos que no implica necesariamente la participación interna, que no implica en definitiva a la propia identidad personal.

La cultura, sin embargo, engloba no sólo el conocimiento de un objeto, sino la participación vital del sujeto. Basta examinar la propia etimología de la palabra. Cultura viene de «colere», que hace referencia a la agricultura, a una tierra cultivada, que permite la germinación del grano. Los granos y las semillas no están ahi como en un depósito, sino que existe una colaboración, una interactividad entre la tierra y la planta. La tierra misma queda modificada por la existencia de la planta. De igual modo la persona cultivada forma un todo con la cultura, modifica y es modificada interiormente.

Por el contrario, la instrucción, como tal, es tan extraña a la vida íntima de la persona que con frecuencia utilizamos términos materiales para designarla: bagaje intelectual (como una especie de equipaje que se lleva a cuestas). En otras palabras, la instrucción es impersonal y la cultura es personal, es decir, integrada en la propia vida del individuo. Por otra parte, poco podía instruir a sus hijos la mujer de época moderna cuando a ella misma se le negaba el acceso a la ciencia.

Recientemente un psicologo norteamericano, Gardner ${ }^{59}$, ha afirmado que no existe un único y monolítico tipo de inteligencia que resulte esencial para el éxito en la vida sino que, en realidad, existe un amplio abanico de no menos de siete variedades distintas de inteligencia. Entre ellas, las que denomina «inteligencias personales», orientadas más que a saber más, a conocerse a sí mismo y a los demás: ejes vertebradores de la educación en la Edad Mođerna.

57 ¿Existe el instinto matemal?... op. cit., pp.45 y ss.

58 La mujer en la Historia, op. cit., pp. 156 y ss.

s9 Citado por Goleman en La inteligencia emocional, Madrid, 1997. 
La familia constituye, en efecto, --lo ha constituido siempre-, el escenario crítico y más apropiado en el que los niños y niñas, los «pequeños ciudadanos», construyen sus hábitos y valores, sus actitudes y creencias más íntimas de cara a las normas de convivencia y de relación entre los seres humanos. La persona ingresa en sociedad a través de la familia, porque ésta es el primer ejercicio de su sociabilidad natural. Como célula o fundamento de la sociedad, la familia de suyo prefigura la cohesión interna y la calidad moral de la sociedad entera. Acerca de una educación excepcional, la del príncipe, don Diego Saavedra Fajardo se expresa en los siguientes términos:

«La segunda obligación natural de los padres es la enseñanza de sus hijos (...) Pero, porque no siempre se hallan en los padres las calidades necesarias para la buena educación de sus hijos, ni pueden atender a ella, conviene entregallos a maestros de buenas costumbres, de sciencia y experiencia (...) sean también de gran valor y generoso espíritu» ${ }^{60}$.

Sin duda es la filosofia que subyace en las disposiciones sinodales ${ }^{61}$, que hacían especial hincapié en que los contrayentes de matrimonio supieran la doctrina cristiana, por cuanto eran futuros padres que deberian educar a sus hijos. En el mismo sentido, también los maestros que quisieran enseñar primeras letras deberían ser examinados, puesto que la labor de educación no se entendía sin el contenido de una doctrina cristiana que equivalía a todo el conjunto de valores sociales ${ }^{62}$. Esto era lo primero que debería aprender el individuo, de forma paralela en la familia y en la escuela -quien fuera a ésta--.

Desde la perspectiva aquí defendida, pues, es indudable la importancia que tienen los entresijos e interacciones - por sutiles que fueran - de la compleja trama de vínculos familiares que tejen la personalidad de todo individuo. Sobre todo en la época moderna, cuando el modelo extenso no había sido suplantado por el nuclear de nuestros días.

${ }^{60}$ Diego de Saavedra Fajardo, Empresas poltticas. Idea de un principe polttico-cristiano. Ed. de Q. Aldea Vaquero, Madrid, Editora Nacional, 1976, p. 378.

61 CSJ, I, VIII, cap. V, fol. 21: Que los que se huvieren de desposar sepan la doctrina christiana.

62 Ibid., I, I, cap. V, fol. 6: Que los maestros de escuela sean examinados. 